\title{
Energy restriction at young age, genetic variants in the insulin-like growth factor pathway and colorectal cancer risk in the Netherlands Cohort Study
}

Citation for published version (APA):

Simons, C. C. J. M., Schouten, L. J., Godschalk, R. W., van Engeland, M., van den Brandt, P. A., van Schooten, F. J., \& Weijenberg, M. P. (2017). Energy restriction at young age, genetic variants in the insulin-like growth factor pathway and colorectal cancer risk in the Netherlands Cohort Study. International Journal of Cancer, 140(2), 272-284. https://doi.org/10.1002/ijc.30439

Document status and date:

Published: 15/01/2017

DOI:

10.1002/ijc.30439

Document Version:

Publisher's PDF, also known as Version of record

Document license:

Taverne

Please check the document version of this publication:

- A submitted manuscript is the version of the article upon submission and before peer-review. There can be important differences between the submitted version and the official published version of record.

People interested in the research are advised to contact the author for the final version of the publication, or visit the DOI to the publisher's website.

- The final author version and the galley proof are versions of the publication after peer review.

- The final published version features the final layout of the paper including the volume, issue and page numbers.

Link to publication

\footnotetext{
General rights rights.

- You may freely distribute the URL identifying the publication in the public portal. please follow below link for the End User Agreement:

www.umlib.nl/taverne-license

Take down policy

If you believe that this document breaches copyright please contact us at:

repository@maastrichtuniversity.nl

providing details and we will investigate your claim.
}

Copyright and moral rights for the publications made accessible in the public portal are retained by the authors and/or other copyright owners and it is a condition of accessing publications that users recognise and abide by the legal requirements associated with these

- Users may download and print one copy of any publication from the public portal for the purpose of private study or research.

- You may not further distribute the material or use it for any profit-making activity or commercial gain

If the publication is distributed under the terms of Article $25 \mathrm{fa}$ of the Dutch Copyright Act, indicated by the "Taverne" license above, 


\title{
Energy restriction at young age, genetic variants in the insulin-like growth factor pathway and colorectal cancer risk in the Netherlands Cohort Study
}

\author{
Colinda C.J.M. Simons ${ }^{1}$, Leo J. Schouten ${ }^{1}$, Roger W. Godschalk ${ }^{2}$, Manon van Engeland ${ }^{3}$, Piet A. van den Brandt ${ }^{1}$, \\ Frederik J. van Schooten ${ }^{2}$ and Matty P. Weijenberg ${ }^{1}$ \\ ${ }^{1}$ Department of Epidemiology, GROW-School for Oncology and Developmental Biology, Maastricht University, Maastricht, the Netherlands \\ ${ }^{2}$ Department of Toxicology, NUTRIM-School for Nutrition and Translational Research on Metabolism, Maastricht University, Maastricht, the Netherlands \\ ${ }^{3}$ Department of Pathology, GROW-School for Oncology and Developmental Biology, Maastricht University Medical Center, Maastricht, the Netherlands
}

The energy restriction (ER)-colorectal cancer (CRC) association is inconsistent in literature. To strengthen the biological plausibility of the ER-CRC association, we investigated whether genetic variation in the insulin-like growth factor (IGF) pathway, a putative underlying mechanism, modulated this association in the Netherlands Cohort Study. Participants completed a questionnaire $(n=120,852)$ and provided toenail clippings for DNA $(-75 \%)$ at baseline. Individuals living in a Western city during the Hunger Winter (1944-45) or Western rural versus non-Western area were exposed to (severe) ER at young age. Genotyping was performed for 3,768 subcohort members and 2,580 CRC cases (case-cohort with 16.3 years follow-up). Cox hazard ratios for CRC were estimated across combined categories of ER and a genetic sum score of unfavorable alleles based on 18 single nucleotide polymorphisms in IGF-related genes and ER and an IGF1 19-CA repeat polymorphism. The reference included ER exposed individuals, so that increased hazard ratios were expected in higher combined categories for calculating relative excess risks due to interaction (additive interactions). Wald tests for multiplicative interactions were also performed. Multiplicative and additive interactions were nonsignificant. Combined ER-genetic sum score categories showed increasing CRC risks in men, but confidence intervals were wide. Women carrying two variant IGF1 19-CA repeat alleles versus those carrying two wild type IGF1 19-CA repeat alleles were at an $\sim 50 \%$ decreased CRC risk, irrespective of ER exposure. In conclusion, data indicate that the IGF pathway might be involved in the ER-CRC association in men, but not women, although interactions were nonsignificant, hampering definite conclusions.

Animal research on energy restriction (ER) and cancer has shown that ER up to $65 \%$, as compared to ad libitum levels, is one of the most effective measures to increase lifespan and reduce cancer risk. ${ }^{1,2}$ These data are intriguing in this era of obesity, with obesity being the result of a positive energy balance and having many adverse health effects, including an increase in colorectal cancer (CRC), ${ }^{3}$ which is a frequent health problem. ${ }^{4}$ Experimental studies on ER in humans are sparse for ethical and methodological reasons and do not include the investigation of long-term effects, such as changes in $\mathrm{CRC}$ risk. ${ }^{5-7}$ Ecological data showed a drop in CRC incidence for birth cohorts born around World War 2 in Norway ${ }^{8}$ and Estonia ${ }^{9}$, against a background of rising CRC incidences over time. Observational data on the association between ER during World War 2 and CRC in cohorts from Russia, ${ }^{10}$ the Netherlands, ${ }^{11}$ and Israel $^{12}$ have shown a decreased CRC risk, ${ }^{11}$ a decreased CRC death risk ${ }^{10}$ and an increased CRC risk, respectively. ${ }^{12}$ The latter study included Israeli Jews who were potentially exposed to the Holocaust

Key words: colon neoplasms, energy restriction, insulin-like growth factors, polymorphisms, rectal neoplasms

Abbreviations used: ADIPOQ: adiponectin; BMI: body mass index; CI: confidence interval; CRC: colorectal cancer; ER: energy restriction; FFQ: food-frequency questionnaire; GH1: growth hormone 1; HR: hazard ratio; HWE: Hardy-Weinberg Equilibrium; IGF1: insulin-like growth factor 1; IGF1R: insulin-like growth factor receptor 1; IGFBP: insulin-like growth factor binding protein; IRS: insulin-receptor substrate; PPARG: peroxisome proliferator-activated receptor gamma; RERI: relative excess risk due to interaction; SNP: single nucleotide polymorphism.

Additional Supporting Information may be found in the online version of this article.

Grant sponsor: World Cancer Research Fund; Grant numbers: 2012/618, 2013/673; Grant sponsor: Dutch Cancer Society; Grant number: 2009-4281; Grant sponsors: Biobanking and Biomolecular Research Infrastructure Netherlands and the Health Foundation Limburg

DOI: $10.1002 /$ ijc.30439

History: Received 23 Feb 2016; Accepted 18 Aug 2016; Online 23 Sep 2016

Correspondence to: Matty P. Weijenberg, Department of Epidemiology, GROW-School for Oncology and Developmental Biology, Maastricht University, P.O. Box 616, 6200 MD Maastricht, the Netherlands, Tel.: +31 43 3882358, Fax: +31 43 3884128, E-mail: mp. weijenberg@maaastrichtuniversity.nl 


\section{What's new?}

Whether energy restriction (ER) impacts colorectal cancer (CRC) risk in humans is unclear, though the potential for such an association is favored by the insulin-like growth factor (IGF) pathway, which can be influenced by ER and putatively stimulates malignant growth. Here, ER at young age and varians in IGF-related genes were simultaneously investigated in relation to CRC in participants of the Netherlands Cohort Study on diet and cancer. The results show that the IGF pathway may be involved in associations between ER at young age and CRC in men, though interactions were not statistically significant. No clear risk pattern was detected in women.

versus those who were not. A possible explanation for the inconsistent finding in this study as opposed to the other studies is that both inverse and positive ER-CRC associations can exist depending on the duration of ER, the severity of ER, the quality of the diet, and the timing of exposure to ER in life. In a systematic literature review, we recently observed that a longer duration of ER might be associated with an increased cancer risk. ${ }^{13}$ Alternatively, there may have been other residual confounding factors present in potential Holocaust survivors, e.g. stress, sleep deprivation, and hygienic circumstances.

Considering the uniqueness of ER exposure, one way to strengthen the evidence for an ER-CRC association is to investigate the mechanisms through which ER influences CRC risk. This will support the biological plausibility of the ER-CRC association, which is an important criterion for establishing causality. ${ }^{14}$ A plausible biological mechanism is the insulin-like growth factor (IGF) pathway, considering findings that link together ER and IGF-related factors, and IGF-related factors and CRC risk. Firstly, a decrease in IGF-1 levels and in the IGF-1:IGF binding protein 3 (IGFBP-3) ratio has been found in caloric restricted animals, although a similar decrease in humans may require a restriction in protein intake specifically. ${ }^{6,15}$ Secondly, adiponectin levels increased with increasing age in caloric restricted animals, ${ }^{16}$ and nuclear protein, mRNA, and DNA binding activity levels of peroxisome proliferatoractivator receptors (PPARs) remained constant with increasing age in caloric restricted rats, whereas (activity) levels decreased with age in ad libitum fed rats. ${ }^{17}$ These effects of caloric restriction on adiponectin and PPARs contribute to better insulin sensitivity, possibly lowering insulin and IGF-1 levels. Lastly, increased IGF-1 levels have been found significantly associated with a $25 \%$ increased CRC risk ( $95 \% \mathrm{CI}=1.08-1.45)$, particularly colon cancer risk, in a meta-analysis of human epidemiological studies. ${ }^{18}$ IGFBP-1 and -3 levels were non-significantly associated with a reduced CRC risk in this meta-analysis. ${ }^{18}$

Here, we investigated interactions between exposure to ER and genetic variants in the IGF pathway, adiponectin (receptors), and PPARG, as markers for IGF pathway involvement, in relation to CRC risk by sex and subsite and we characterized joint effects.

\section{Subjects and Methods Population and design}

The Netherlands Cohort Study on diet and cancer (NLCS) includes 120,852 men and women who were between 55 and
69 years old at baseline in 1986, when completing a selfadministered questionnaire. ${ }^{19} \sim 75 \%$ of participants also returned toenail clippings. The NLCS was approved by the review boards of the TNO Nutrition and Food Research Institute (Zeist, the Netherlands) and Maastricht University (Maastricht, the Netherlands). The NLCS is characterized by a casecohort approach for reasons of efficiency, in which a subcohort $(n=5000)$, randomly selected immediately after baseline and independent of any exposure, is followed up through linkage to the Central Bureau of Genealogy and municipal registries to estimate the accumulated person-time at risk $(>99.9 \%$ completeness). The whole cohort is followed up for incident cancer cases through linkage to the population-based cancer registry and PALGA (the Netherlands pathology database) (>96\% completeness). ${ }^{20,21}$ Participants who reported a history of cancer (other than skin cancer) on the baseline questionnaire were excluded from follow-up. This left 4,774 subcohort members and 3,440 incident CRC cases (ICD-O 153-154) after a followup of 16.3 years. Toenail DNA was isolated according to the DNA extraction protocol of Cline et al. ${ }^{22}$ with some adjustments. ${ }^{23}$ Toenails are a valid long-term DNA source for SNP genotyping in large-scale epidemiological studies. ${ }^{24}$ Toenail DNA was available for 3,768 subcohort members (78.9\%) and 2,580 CRC cases (75.0\%), of which 114 CRC cases were also subcohort members. Consequently, we had available a total of 6,234 unique toenail DNA samples for genotyping.

\section{ER exposure and covariates}

ER exposure was based on area-exposure data derived from the baseline questionnaire. Subcohort members and CRC cases were between 12 and 28 years old at the time of the Dutch Hunger Winter in 1944-45. According to Stein et al. ${ }^{25} 11$ Western cities are considered famine cities: Amsterdam, Rotterdam, The Hague, Utrecht, Zaandam, Hilversum, Amersfoort, Dordrecht, Vlaardingen/Schiedam, Delft and Leiden. At the height of the famine, between December 1944 and April 1945, official daily rations per capita were 400-800 kilocalories, although the diet remained nutritionally balanced. ${ }^{2,27}$ We distinguish between participants who lived in a non-Western area during the Hunger Winter, Western rural area, and Western city, as reported by participants on the baseline questionnaire. Other available proxy variables for ER were the place of residence during the War Years in 1940-44 (urban versus rural) and whether or not an individual's father was employed during the Economic Depression in 1932-40. Nutritional differences existed 
during these years, although the contrast was smaller than during the Hunger Winter, i.e. sufficient calories were available, but the variation in the food pattern was more limited. For this reason, we view the Hunger Winter as our main exposure (further information is available in the Online Supplemental Material).

Covariates were also derived from the baseline questionnaire, which included a semi-quantitative 150 -item food frequency questionnaire (FFQ). Comparison with a 9-day dietary record showed that it ranked subjects adequately according to intake of the food groups and nutrients investigated. ${ }^{28}$ The FFQ was found to be a good indicator of nutrient intake over a period of $\geq 5$ years. ${ }^{29}$

\section{Single nucleotide polymorphisms in IGF-related genes} Our selection of single nucleotide polymorphisms (SNPs) in IGF-related genes was based on literature and has been described before. ${ }^{30}$ The quality control of genotyping resulted in some exclusions, leaving 5,697 samples with at least $95 \%$ call rate (i.e. one SNP was missing at most). ${ }^{30}$ We generated an unweighted genetic sum score of unfavorable alleles using 18 SNPs in 8 genes, as shown in Supporting Information Table 1, for which the literature was unequivocal about which allele was the unfavorable allele. The genetic sum score was divided into tertiles as based on the distribution in the subcohort to maintain optimal power for estimating the CRC risk associated with combined categories of ER and the genetic sum score. One hundred and thirty-four subcohort members and 120 CRC cases could not be categorized because of missing SNP data. Additional details are available in the Online Supplemental Material.

\section{IGF1 19-CA repeat polymorphism}

In addition to SNPs, an IGF1 19-CA repeat polymorphism was selected for genotyping, because it has been associated with CRC risk. $^{31-34}$ Genotyping was performed as described before ${ }^{30}$ and in the Online Supplemental Material. The IGF1 19-CA repeat polymorphism was categorized according to Rosen et al. ${ }^{35}$ distinguishing between individuals homozygous for the wild type allele (19/19 CA repeats), heterozygous individuals (19/non-19 CA repeats), and individuals carrying two variant alleles (non-19/ non-19 CA repeats). Previous studies showed increased ${ }^{31-33}$ and decreased CRC risks ${ }^{34}$ for variant repeat alleles.

\section{Statistics}

Baseline differences according to ER exposure were studied using $\chi^{2}$ and ANOVA tests, as appropriate. We estimated sex- and subsite-specific hazard ratios (HRs) for CRC and 95\% confidence intervals (95\% CIs) for linear combinations of ER and genetic variables using Cox regression, while adjusting for potential confounders. Potential confounders were predefined on the basis of literature $\mathrm{s}^{3,11,30}$ : age, first-degree family history of CRC, smoking status, alcohol intake, meat intake, processed meat intake, total energy intake, body mass index (BMI), and occupational physical activity in men ${ }^{36}$ and non-occupational physical activity in women. ${ }^{36}$ ER exposed individuals (i.e. Western city residents during the Hunger Winter) in the lowest genetic sum score tertile were used as the reference group. This is contrary to what we did in previous studies, in which those who lived in a nonWestern area during the Hunger Winter were used as the reference group, yielding a decreased CRC risk to be associated with ER exposure in men. ${ }^{11}$ However, it was necessary to switch reference groups for ER variables because the relative excess risk due to interaction (RERI), which is a measure for additive interaction, can only be calculated when coding variables such that the highest combined category is expected to increase risk. Even though we previously observed decreased CRC risks across subsites in women carrying two variant IGF1 19-CA repeat alleles versus those carrying two wild type IGF1 19-CA repeat alleles, we refrained from recoding the IGF1 19-CA repeat polymorphism. Reasons for this were inconsistent literature findings ${ }^{31-34}$ and that we previously also observed an increased overall CRC risk in men carrying two variant IGF1 19-CA repeat alleles versus those carrying two wild type IGF1 19-CA repeat alleles, when analyzing this repeat polymorphism separately ${ }^{30}$ and in combination with body size. ${ }^{37}$ For comparability, we kept the coding of the IGF1 19-CA repeat polymorphism the same in men and women, but we did not show RERIs in women, because these are only interpretable when higher combined categories are expected to increase risk. The RERI was derived from the formula $R E R I=R R_{11}-R R_{10}-R R_{01}+1{ }^{38}$ in which $R R$ denotes relative risk and 1 and 0 denote comparison versus reference categories, with the position of this number denoting the first and second exposure of two combined exposures. Corresponding 95\% biascorrected confidence intervals were estimated by bootstrapping (n bootstrap samples $=1,000) .{ }^{39}$ In addition, we tested multiplicative interactions using the Wald test. To account for the additional variance introduced by sampling the subcohort from the entire cohort, standard errors were estimated using the robust Huber-White sandwich estimator. ${ }^{40}$ The proportional hazards assumption was tested using the scaled Schoenfeld residuals and by visually inspecting the -log-log-transformed hazard curves (there were no apparent violations). To check for the influence of preclinical disease, a sensitivity analysis was conducted in which the first 2 years of follow-up were excluded (with no essential changes in results). Analyses were conducted using Stata version 12 (Stata Corp., College Station, TX). Statistical significance was indicated by a $p$ value $<0.05$ for two-sided testing.

\section{Results}

\section{Baseline characteristics}

Figure 1 shows a flow diagram of the available number of subcohort members and CRC cases for each combination of ER variables and genetic variables (irrespective of missing values on potential confounders). Participants with an inconsistent or incomplete FFQ were excluded. The genetic sum score as based on the distribution in the subcohort was generated after this exclusion step and the range of unfavorable alleles was 6-14, 15-18, and 19-29 in the lowest, middle, and highest tertile, respectively. 


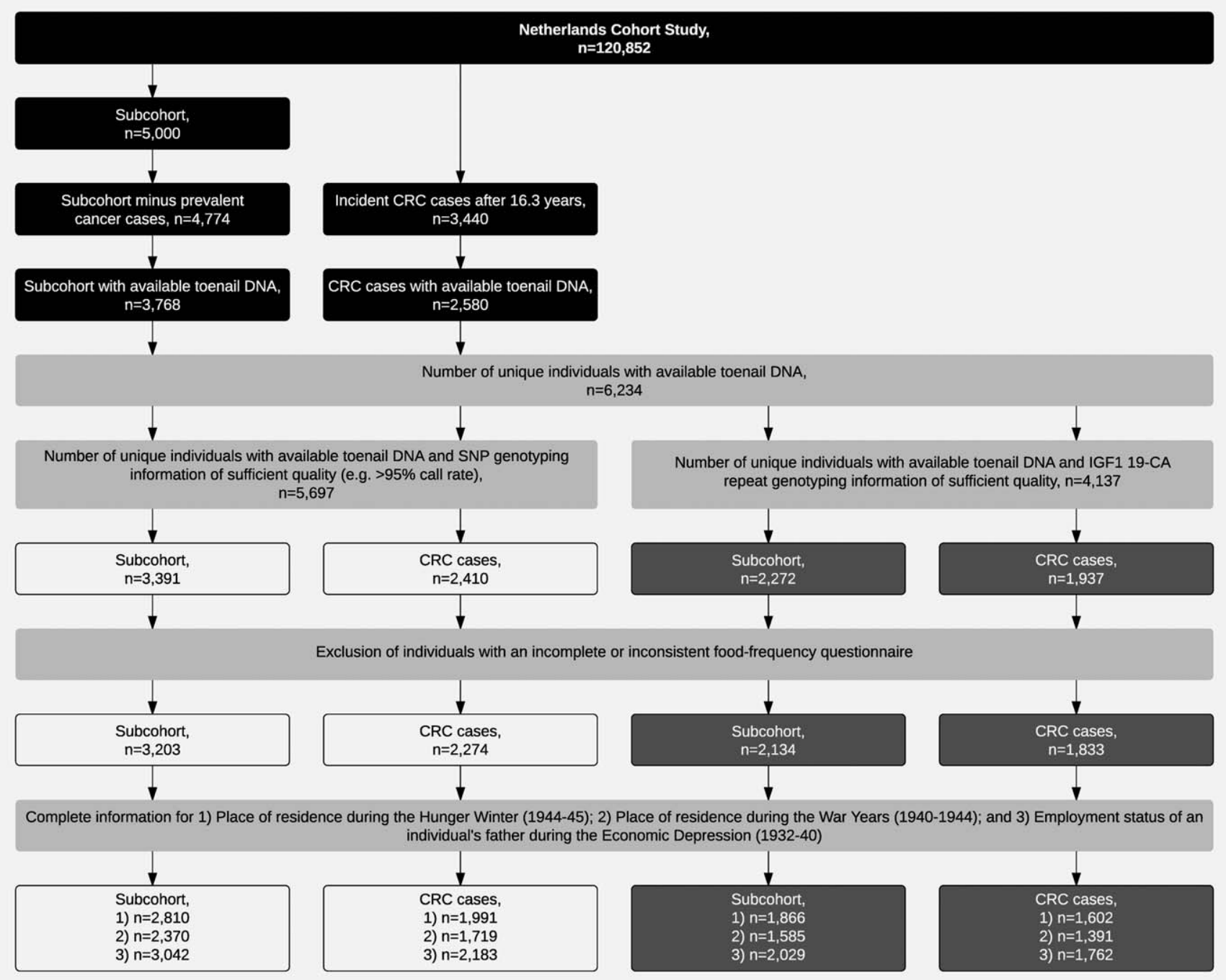

Figure 1. Flow diagram of available subcohort members and colorectal cancer cases in this study within the Netherlands Cohort Study.

Table 1 shows the number of male and female subcohort members across categories of genetic variables and potential confounders according to the place of residence during the Hunger Winter. In general, men living in a non-Western area during the Hunger Winter were younger $(p$ value $=0.02$ ), had a higher intake of meat $(p$ value $=0.02)$ and processed meat ( $p$ value $<0.001$ ), had a higher BMI ( $p$ value $<0.001$ ), and were relatively less often engaged in high levels of occupational physical activity ( $p$ value $=0.003$ ) than men living in a Western area during the Hunger Winter. Women living in a non-Western area during the Hunger Winter were less often (ex-)smokers ( $p$ value $=0.02$ ) and had a higher intake of processed meat ( $p$ value $<0.001)$ and total energy at baseline $(p$ value $=0.03)$ than women living in a Western area during the Hunger Winter. There were no significant differences in genetic variables, firstdegree family history of colorectal cancer and alcohol intake in men and women, smoking and total energy intake in men, and meat intake, BMI and non-occupational physical activity in women according to the place of residence during the Hunger Winter.

\section{Joint effects of ER exposures and genetic variation in the IGF pathway}

There were no multiplicative or additive interactions between the place of residence during the Hunger Winter and the genetic sum score of unfavorable alleles in the IGF pathway in relation to the risk of CRC overall and by subsite in both men (Table 2) and women (Table 3). Increasing CRC risks were observed across combined categories of exposure to the Hunger Winter and the genetic sum score in men, but such a trend was not evident in women. Hazard ratios (95\% CIs) for CRC comparing ER exposed men in the highest genetic sum score tertile (genetic effect), ER unexposed men in the lowest genetic sum score tertile (effect of absence of ER), and 


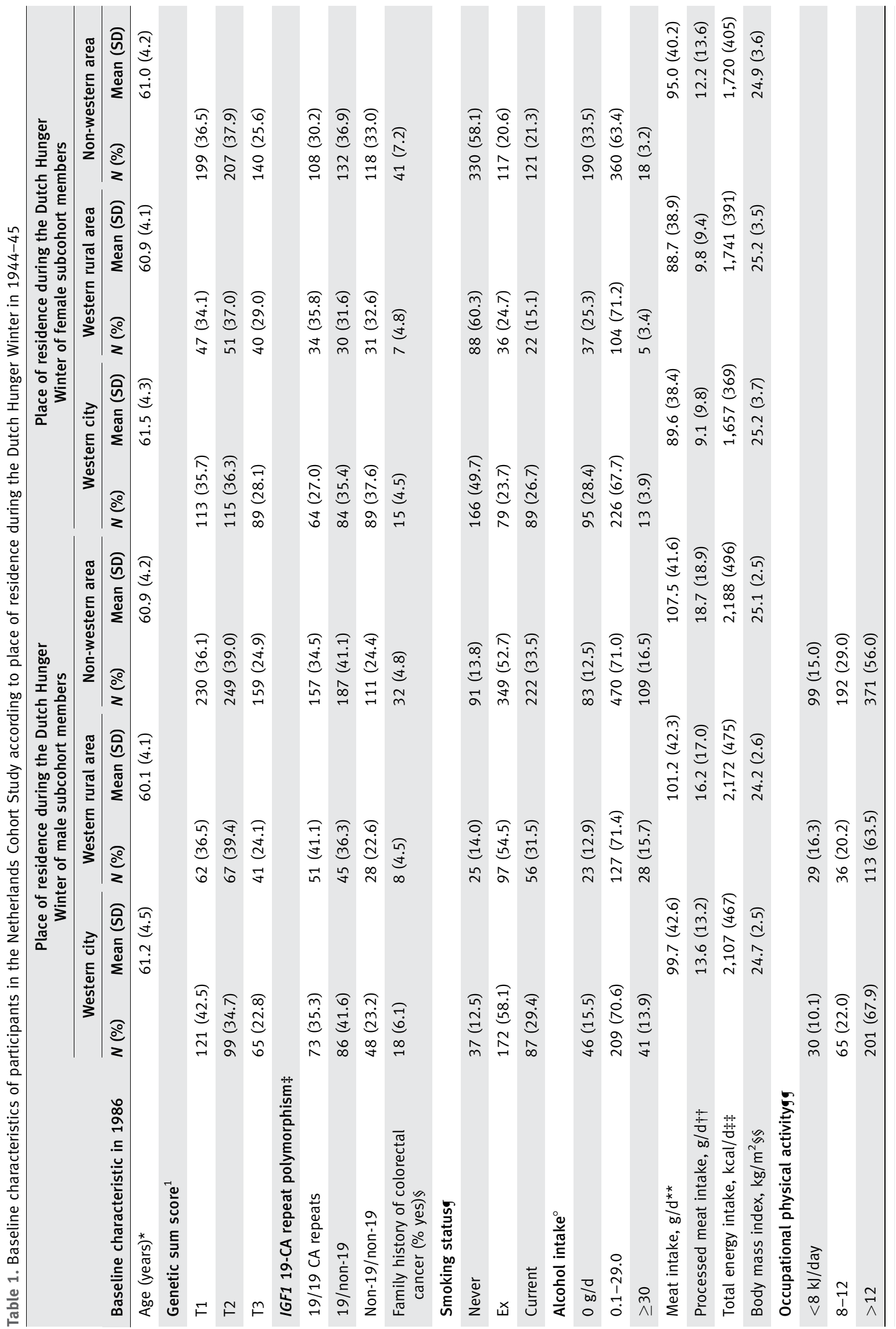




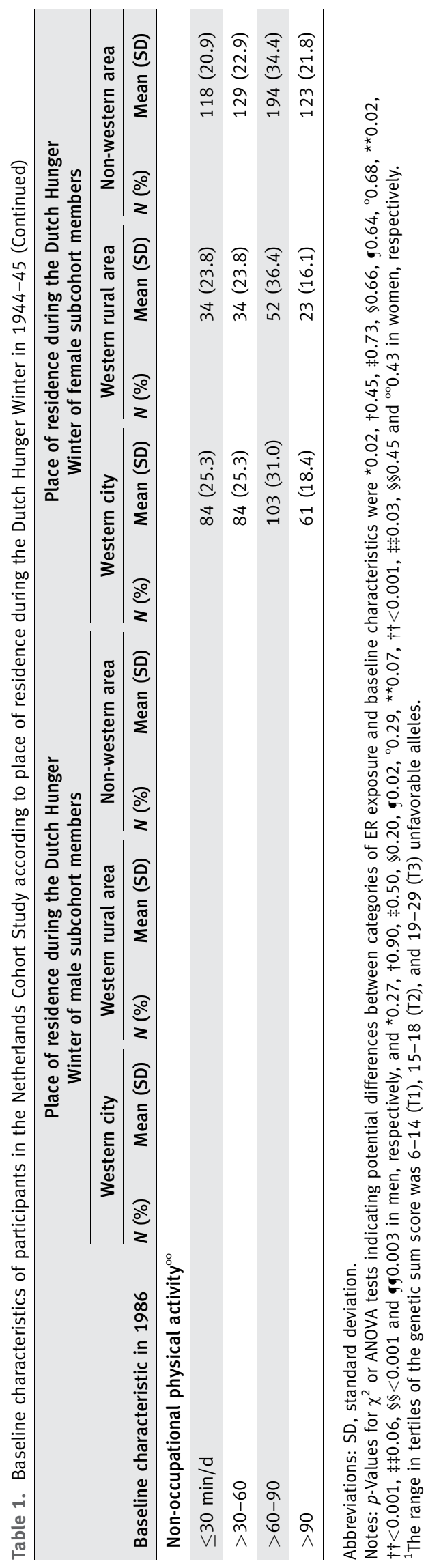

ER unexposed men in the highest genetic sum score tertile (joint effect) relative to ER exposed men in the lowest genetic sum score tertile, which were hypothesized to be at lowest risk and thus used as reference, were: 1.23 (0.74 to 2.04), 1.51 (1.03 to 2.20 ), and 2.04 (1.39 to 3.00 ), respectively. However, even though several hazard ratios across combined categories reached statistical significance, confidence intervals were wide and overlapping. Results by subsite did not clarify associations further.

There were also no interactions between the place of residence during the Hunger Winter and the IGF1 19-CA repeat polymorphism in relation to the risk of CRC overall and by subsite in both men (Table 4) and women (Table 5). Women carrying two variant repeat alleles (non-19 CA repeats) versus women carrying two wild type alleles (19 CA repeats) were found to have strongly decreased CRC risks, irrespective of ER exposure. This result was consistent across colon subsites, but not observed in relation to rectal cancer.

When considering the place of residence during the War Years and the employment status of an individual's father during the Economic Depression in interaction with the genetic sum score, no interactions were observed in relation to the risk of CRC overall and by subsite in men and women (Supporting Information Tables 2-5). When considering the place of residence during the War Years and the employment status of an individual's father during the Economic Depression in interaction with the IGF1 19-CA repeat polymorphism, multiplicative interactions in relation to CRC, in particular proximal colon cancer, were observed in women but not men (Supporting Information Tables 6-9). Similar to results for combined categories of ER exposure during the Hunger Winter and IGF1 19-CA repeat status, women carrying two variant repeat alleles as compared to women carrying two wild type repeat alleles were at a decreased risk of CRC, irrespective of ER exposure during the War Years or Economic Depression (Supporting Information Tables 7 and 9).

\section{Discussion}

We investigated whether genetic variation in IGF-related genes modified the ER-CRC association. Multiplicative and additive interactions between ER variables and genetic variation in the IGF pathway in relation to CRC were not statistically significant in men and women. There was indication of a pattern of increasing CRC risks across combined categories of ER-genetic sum score combinations in men, but not women. However, confidence intervals around hazard ratios were wide and overlapping, making it difficult to conclude whether hazard ratios in higher combined categories differed significantly, and chance findings cannot be excluded. It should be noted that for the purpose of assessing additive interactions, we changed the reference group of the ER variables to ER exposed individuals instead of unexposed individuals, which were used as reference in our previous studies. Previously, in the NLCS, ER exposed versus unexposed men, but not women, were found to be at a decreased CRC risk. ${ }^{11}$ The genetic 


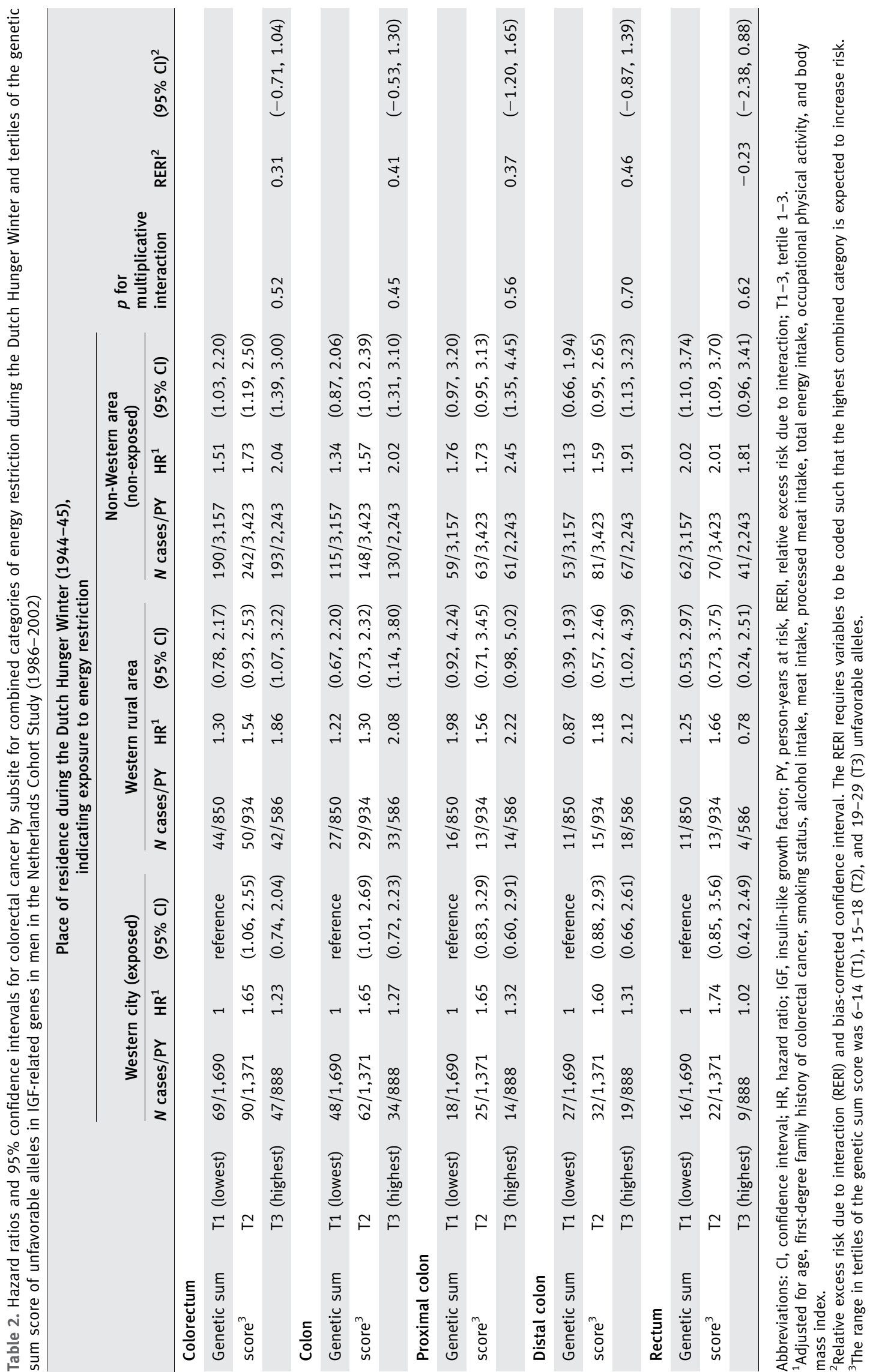




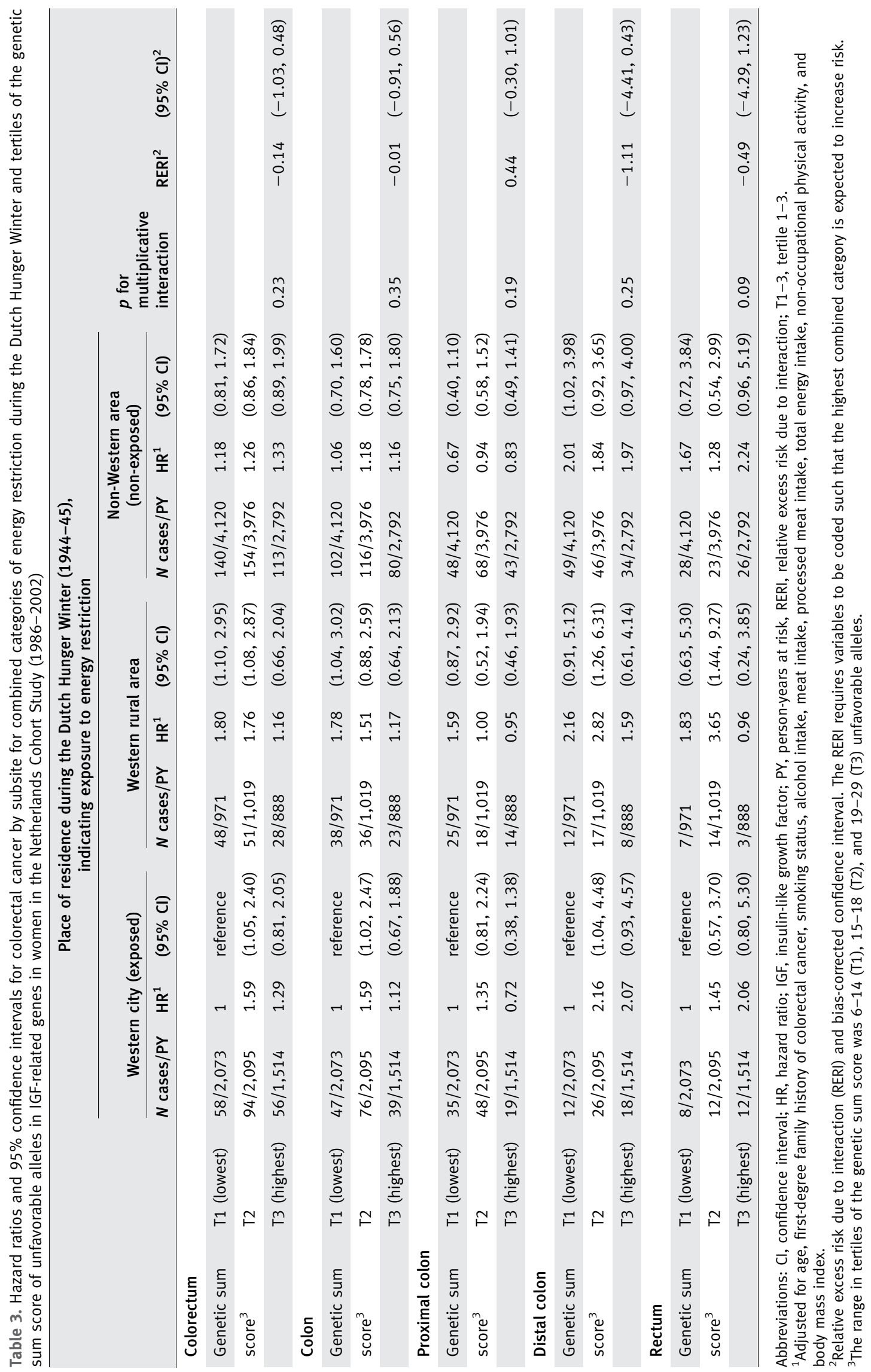




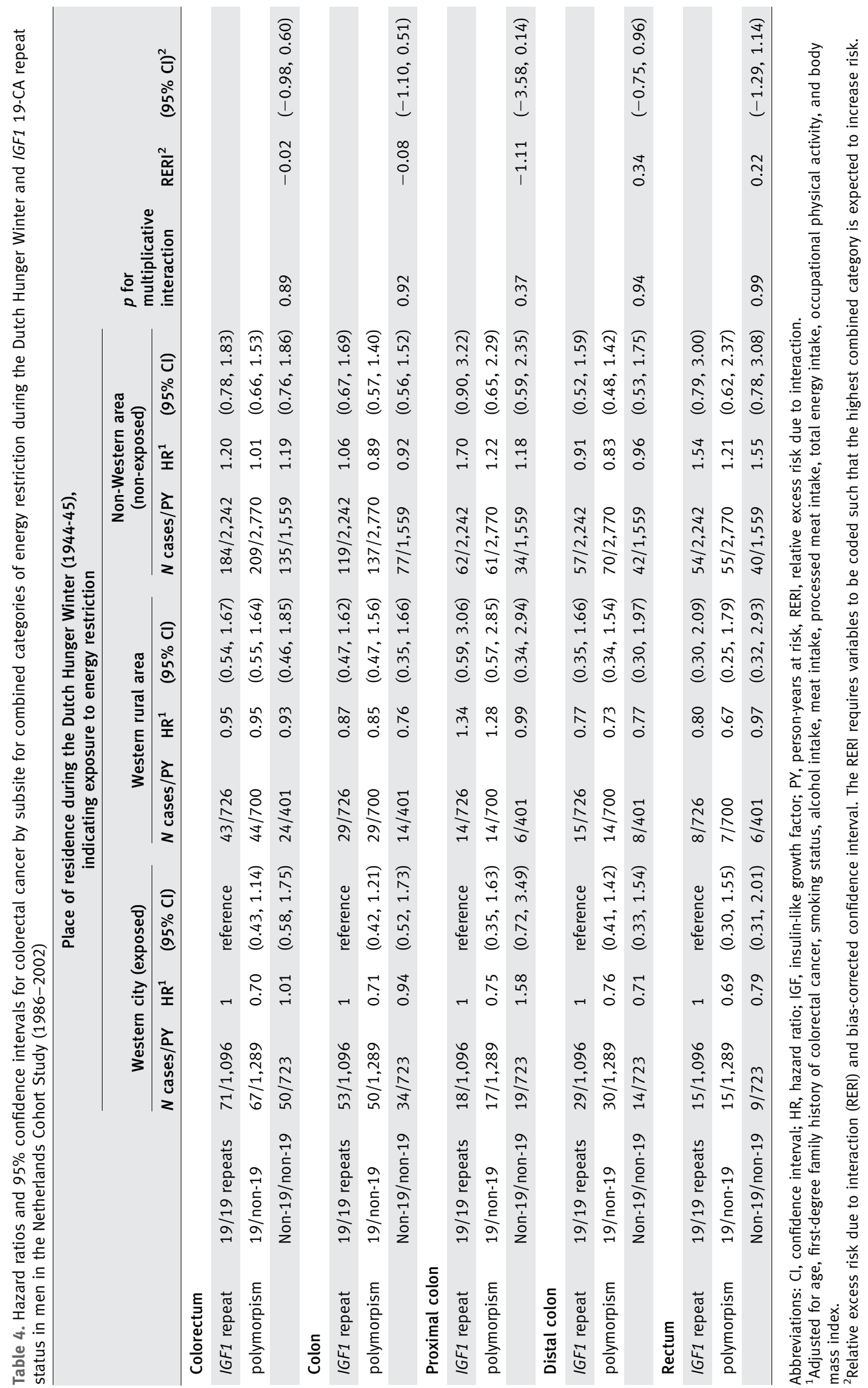




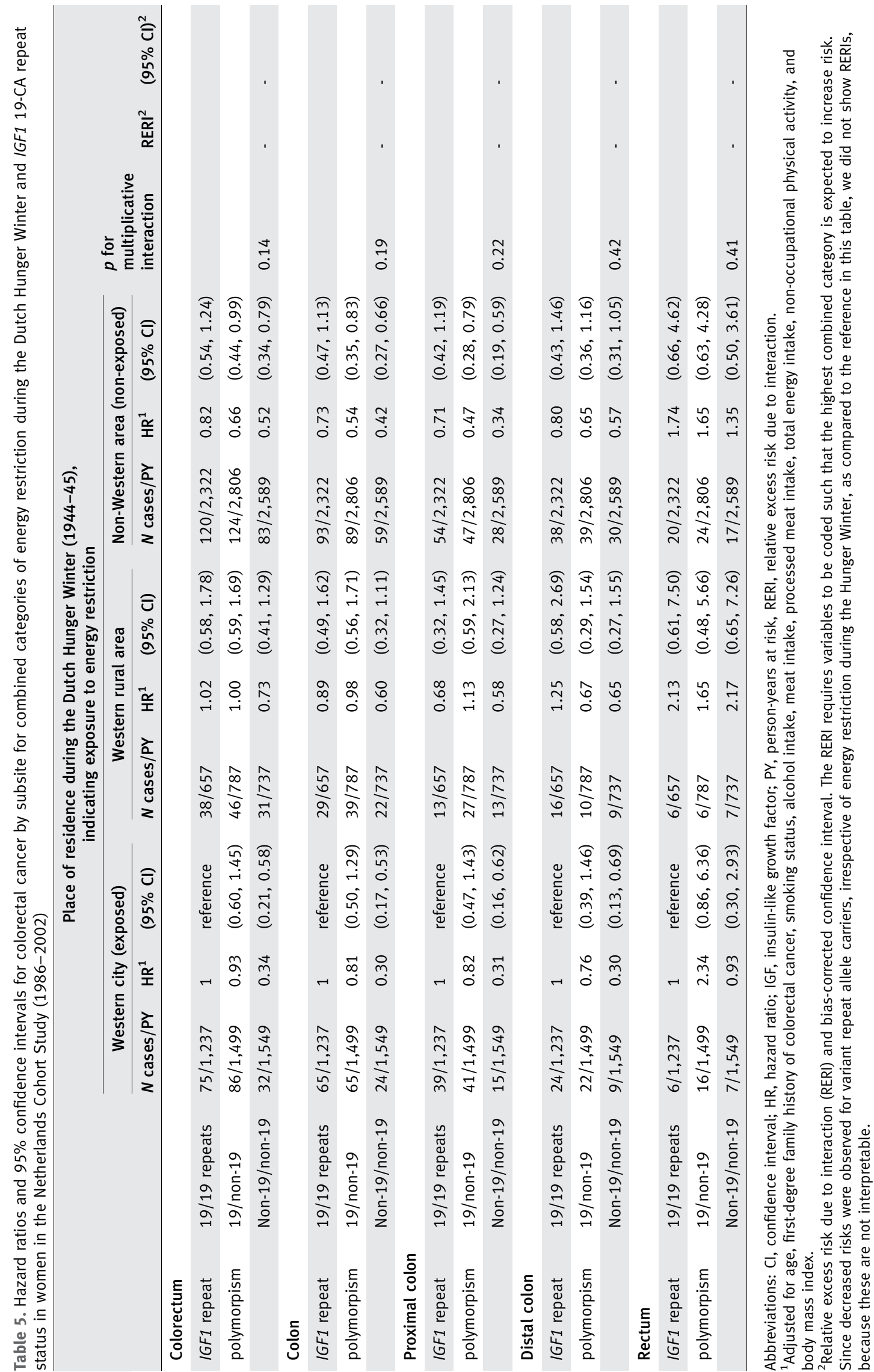


sum score of unfavorable alleles in IGF pathway genes was previously associated with an increased CRC risk in men, but not women. ${ }^{30}$ When we previously considered interactions between indicators of body size and this genetic sum score, we found that a larger body size was a CRC risk factor in men, but not women, in the presence of an accumulation of unfavorable alleles in the IGF pathway, although also no significant interactions were observed. ${ }^{37}$ Variant IGF1 19-CA repeat alleles have been consistently associated with decreased CRC risks in women in the NLCS, irrespective of ER in the present study and body size in a previous study. ${ }^{37}$

The absence of significant interactions in the presence of a CRC risk pattern in men across categories of ER exposure and the genetic sum score prevents definite conclusions. Nonsignificant interactions could be because of insufficient power, even though large case numbers were available. It is known that a four times larger sample size is needed to detect an interaction effect as compared to a marginal effect of similar magnitude, ${ }^{41}$ making power a common issue in gene-environment interaction $(\mathrm{GxE})$ research. Still, a higher number of significant interactions has been reported in the GxE field as would be expected on the basis of chance alone, but few interactions have been consistently replicated, which suggests publication bias or false positives. ${ }^{42,43}$ In this regard, there may often be a a trade-off between high-quality exposure data and sample size. ${ }^{42}$ The present study included detailed baseline exposure information and had a nearly complete follow-up. In addition, next to testing both multiplicative and additive interactions, because interactions may be scale-dependent, we felt it important to characterize joint effects by looking at potential risk patterns.

The observed CRC risk pattern in men across categories of ER exposure and the genetic sum score is biologically plausible, as described in the introduction. The biological plausibility of involvement of the IGF pathway in the ERCRC association is further indicated by mice studies that showed that caloric restriction, inducing a lean phenotype, decreased IGF-1 blood levels ${ }^{44-46}$ and increased IGFBP-3 ${ }^{46}$ and adiponectin blood levels ${ }^{45}$, next to increasing the time to palpable tumor ${ }^{44}$ and decreasing the volume ${ }^{45}$ or number of (induced) tumors. ${ }^{46}$ These animal models cannot explain the heterogeneity found in results between men and women. However, it has long been recognized that insulin-like growth factor, insulin, and hormonal axes may interact, explaining differences in obesity-CRC associations between men and women. For example, an association has been observed between obesity and CRC in men and premenopausal women, but less clearly in postmenopausal women. ${ }^{47} \mathrm{~A}$ putative explanation for this relates to that obesity is correlated with estrogen levels in postmenopausal women, in which androgen to estrogen conversion in adipose tissue is the main source of estrogen, whereas ovarian production of estrogens mainly determines estrogen levels in premenopausal women. ${ }^{47}$ Higher postmenopausal endogenous hormone levels ${ }^{48}$ and postmenopausal hormone use ${ }^{49}$ have been associated with a decreased CRC risk. Therefore, it is thought that estrogens may counter the risk-increasing influence of obesity in postmenopausal women. ${ }^{47}$ In parallel, in response to moderate aerobic exercise combined with caloric restriction, estrogen levels have been reported to decrease in premenopausal women, ${ }^{50}$ and the protective effect of ER in women at young age, which favorably influences insulin-like growth factor and insulin levels, might be weakened by a simultaneous drop in estrogen levels. In the present study, ER exposure occurred at young age before, during or after menarche, but the vast majority of women in the NLCS was exposed after menarche ${ }^{11}$ and thus exposure was premenopausal. NLCS participants came under observation since 1986 when at least 55 years old, rendering the vast majority of incident female CRC cases in this study postmenopausal. It would be interesting for future research to explore a three-way interaction between ER at young age, BMI at adult age, and genetic variation in the IGF pathway, for which we had too limited power at present.

Strengths of the present study include the prospective character and long follow-up. The long follow-up for cancer incidence ( 16.3 years) resulted in large case numbers and substantial power, but, as a limitation, may have attenuated associations with increasing follow-up time. Unfortunately, the relatively small proportion of individuals exposed to ER did not allow for the exploration of combined categories of ER and genetic variables in relation to CRC risk according to different follow-up periods. The use of area-exposure data as proxies for ER was validated within our cohort, as $80 \%$ of women who reported severe hunger also reported living in a Western city during the Hunger Winter. ${ }^{51}$ Strengths of this study also include the availability of information on many potential confounders in diet and lifestyle, minimizing residual confounding. This is important, because in any study investigating ER exposure at young age and later life CRC risk, other risk and protective factors will have accumulated in individuals between the age of ER exposure and baseline measurements. We did not adjust for multiple testing, because our study was hypothesisbased and the genetic sum score greatly reduced the number of tests that had to be performed. Although this may be considered a limitation by some, we were most interested in characterizing joint effects between ER and genetic variation in the IGF pathway, as opposed to discovering genetic variants affecting the risk of CRC, for which guarding for type I errors is most important (though increasing the chances of type II errors). ${ }^{42,52}$ In retrospect, adjustment would not have changed our results (i.e. most results were nonsignificant).

To conclude, these unique data on ER and CRC indicate that the IGF pathway might be involved in the ER-CRC association in men, but not women, although multiplicative and additive interactions were nonsignificant, hampering definite conclusions.

\section{Acknowledgements}

The authors are indebted to the participants of this study and wish to thank the Netherlands Cancer Registry and the Netherlands nationwide registry of pathology (PALGA). They also thank Drs. A. Volovics, and A. Kester for 
statistical advice; S. van de Crommert, H. Brants, J. Nelissen, C. de Zwart, M. Moll, W. van Dijk, and A. Pisters for data management; H. van Montfort, T. van Moergastel, L. van den Bosch, R. Schmeitz, and J. Berben for programming assistance; L. Jonkers, J. Goessens, K. Lemmens, and S. Lumeij for the laboratory work involved; and the Biobank Maastricht UMC+ for sample storage.

\section{References}

1. Elias SG, Peeters PHM, Grobbee DE, et al. Transient caloric restriction and cancer risk (The Netherlands). Cancer Causes Control 2007; 18:15.

2. Roberts SB, Speakman J. Update on human calorie restriction research. Adv Nutr Bethesda Md 2013; 4:563-4.

3. Colorectal cancer | Continuous Update Project | WCRF [Internet]. [cited May 10, 2015]; Available from: http://www.wcrf.org/cancer_research/cup/ key_findings/colorectal_cancer.php

4. Jemal A, Bray F, Center MM, et al. Global cancer statistics. CA Cancer J Clin 2011; 61:69-90.

5. Heilbronn LK, Ravussin E. Calorie restriction and aging: review of the literature and implications for studies in humans. Am J Clin Nutr 2003; 78: 361-9.

6. Fontana L. Calorie restriction and cardiometabolic health. Eur J Cardiovasc Prev Rehabil 2008; 15:3-9.

7. Rickman AD, Williamson DA, Martin CK, et al. The CALERIE Study: design and methods of an innovative $25 \%$ caloric restriction intervention. Contemp Clin Trials 2011; 32:874-81.

8. Svensson E, Grotmol T, Hoff G, et al. Trends in colorectal cancer incidence in Norway by gender and anatomic site: an age-period-cohort analysis. Eur J Cancer Prev 2002; 11:489-95.

9. Svensson E, Møller B, Tretli S, et al. Early life events and later risk of colorectal cancer: ageperiod-cohort modelling in the Nordic countries and Estonia. Cancer Causes Control 2005; 16: 215-23.

10. Koupil I, Plavinskaja S, Parfenova N, et al. Cancer mortality in women and men who survived the siege of Leningrad (1941-1944). Int J Cancer 2009; 124:1416-21.

11. Hughes LAE, van den Brandt PA, Goldbohm RA, et al. Childhood and adolescent energy restriction and subsequent colorectal cancer risk: results from the Netherlands Cohort Study. Int J Epidemiol 2010; 39:1333-44.

12. Keinan-Boker L, Vin-Raviv N, Liphshitz I, et al. Cancer incidence in Israeli Jewish survivors of World War II. J Natl Cancer Inst 2009; 101: 1489-500.

13. Elands R, Simons CCJM, Dongen M van, Schouten L, Verhage BAJ, Brandt P van, Weijenberg MP. A Systematic Literature Review and Meta-regression Analysis on Early-life Energy Restriction and Cancer Risk in Humans. PLoS One 2016; 11:e0158003.

14. Hill AB. The environment and disease: association or causation? Proc R Soc Med 1965; 58:295300.

15. Sonntag WE, Lynch CD, Cefalu WT, et al. Pleiotropic effects of growth hormone and insulin-like growth factor (IGF) -1 on biological aging: inferences from moderate caloric-restricted animals. J Gerontol a Biol Sci Med Sci 1999; 54:B521-538.

16. Speakman JR, Mitchell SE. Caloric restriction. Mol Aspects Med 2011; 32:159-221.

17. Sung B, Park S, Yu BP, et al. Modulation of PPAR in aging, inflammation, and calorie restriction. J Gerontol a Biol Sci Med Sci 2004; 59:9971006.
18. Chi F, Wu R, Zeng Y, et al. Circulation insulinlike growth factor peptides and colorectal cancer risk: an updated systematic review and meta-analysis. Mol Biol Rep 2013; 40:3583-90.

19. van den Brandt PA, Goldbohm RA, van 't Veer $\mathrm{P}$, et al. A large-scale prospective cohort study on diet and cancer in The Netherlands. J Clin Epidemiol 1990; 43:285-95.

20. Goldbohm RA, van den Brandt PA, Dorant E Estimation of the coverage of Dutch municipalities by cancer registries and PALGA based on hospital discharge data. Tijdschr Soc Gezondheidsz 1994; 72:80-84.

21. Casparie M, Tiebosch ATMG, Burger G, et al. Pathology databanking and biobanking in The Netherlands, a central role for PALGA, the nationwide histopathology and cytopathology data network and archive. Cell Oncol 2007; 29: 19-24.

22. Cline RE, Laurent NM, Foran DR. The fingernails of Mary Sullivan: developing reliable methods for selectively isolating endogenous and exogenous DNA from evidence. J Forensic Sci 2003; 48:32833.

23. van Breda SG, Hogervorst JG, Schouten LJ, et al. Toenails: an easily accessible and long-term stable source of DNA for genetic analyses in large-scale epidemiological studies. Clin Chem 2007; 53: 1168-70.

24. Hogervorst JGF, Godschalk RWL, van den Brandt PA, et al. DNA from nails for genetic analyses in large-scale epidemiologic studies. Cancer Epidemiol Biomark Prev 2014; 23:2703-12.

25. Stein Z, Susser M, Saenger G, et al. Famine and Human Development, The Dutch Hunger Winter of 1944-1945. New York, NY: Oxford University Press, 1975.

26. Burger G, Sandstead H, Drummond J. Malnutrition and Starvation in Western Netherlands, September 1944 to July 1945. Part I and II. The Hague, the Netherlands: General State Printing Office, 1948.

27. Trienekens G. Tussen ons volk en de honger. De voedselvoorziening, 1940-45. (English translation: Between our nation and the hunger. The food supply, 1940-45). Utrecht, the Netherlands: Stichting Matrijs, 1985.

28. Goldbohm RA, van den Brandt PA, Brants HA, et al. Validation of a dietary questionnaire used in a large-scale prospective cohort study on diet and cancer. Eur J Clin Nutr 1994; 48:253-65.

29. Goldbohm RA, van 't Veer P, van den Brandt PA, et al. Reproducibility of a food frequency questionnaire and stability of dietary habits determined from five annually repeated measurements. Eur J Clin Nutr 1995; 49:420-9.

30. Simons CCJM, Schouten LJ, Godschalk RWL, et al. Genetic Variants in the Insulin-like Growth Factor Pathway and Colorectal Cancer Risk in the Netherlands Cohort Study. Sci Rep 2015; 5: 14126

31. Morimoto LM, Newcomb PA, White E, et al. Insulin-like growth factor polymorphisms and colorectal cancer risk. Cancer Epidemiol Biomark Prev 2005; 14:1204-11.
32. Slattery ML, Murtaugh M, Caan B, et al. Energy balance, insulin-related genes and risk of colon and rectal cancer. Int J Cancer 2005; 115: 148-54.

33. Samowitz WS, Wolff RK, Ma KN, et al. Polymorphisms in insulin-related genes predispose to specific KRAS2 and TP53 mutations in colon cancer. Mutat Res 2006; 595:117-24.

34. Keku TO, Vidal A, Oliver S, et al. Genetic variants in IGF-I, IGF-II, IGFBP-3, and adiponectin genes and colon cancer risk in African Americans and Whites. Cancer Causes Control 2012; 23: 1127-38.

35. Rosen CJ, Kurland ES, Vereault D, et al. Association between serum insulin growth factorI (IGF-I) and a simple sequence repeat in IGF-I gene: implications for genetic studies of bone mineral density. J Clin Endocrinol Metab 1998; 83:2286-90.

36. Simons CCJM, Hughes LAE, van Engeland M, et al. Physical activity, occupational sitting time, and colorectal cancer risk in the Netherlands cohort study. Am J Epidemiol 2013; 177:514-30.

37. Simons CCJM, Schouten LJ, Godschalk R, et al. Body size, physical activity, genetic variants in the insulin-like growth factor pathway and colorectal cancer risk. Carcinogenesis 2015; 36: 971-81.

38. Rothman KJ, Greenland S. Modern Epidemiology. Philadelphia: Lippincott-Raven Publishers, 1998.

39. Carpenter J, Bithell J. Bootstrap confidence intervals: when, which, what? A practical guide for medical statisticians. Stat Med 2000; 19:114164.

40. Barlow WE. Robust variance estimation for the case-cohort design. Biometrics 1994; 50:1064-72.

41. Aschard H, Lutz S, Maus B, et al. Challenges and opportunities in genome-wide environmental interaction (GWEI) studies. Hum Genet 2012; 131:1591-613.

42. Hutter CM, Mechanic LE, Chatterjee N, NCI Gene-Environment Think Tank, et al. Gene-environment interactions in cancer epidemiology: a National Cancer Institute Think Tank report. Genet Epidemiol 2013; 37:643-57.

43. Simonds NI, Ghazarian AA, Pimentel CB, et al. Review of the Gene-Environment Interaction Literature in Cancer: What Do We Know?. Genet Epidemiol 2016; 40:356-65.

44. Wheatley KE, Williams EA, Smith NCP, et al. Low-carbohydrate diet versus caloric restriction: effects on weight loss, hormones, and colon tumor growth in obese mice. Nutr Cancer 2008; 60:61-8.

45. Harvey AE, Lashinger LM, Otto G, et al. Decreased systemic IGF-1 in response to calorie restriction modulates murine tumor cell growth, nuclear factor- $\mathrm{\kappa B}$ activation, and inflammationrelated gene expression. Mol Carcinog 2013; 52: 997-1006.

46. Olivo-Marston SE, Hursting SD, Perkins SN, et al. Effects of calorie restriction and dietinduced obesity on murine colon carcinogenesis, growth and inflammatory factors, and microRNA expression. PloS One 2014; 9:e94765 
47. Giovannucci E. Obesity, gender, and colon cancer. Gut 2002; 51:147-147

48. Murphy N, Strickler HD, Stanczyk FZ, et al. A Prospective Evaluation of Endogenous Sex Hormone Levels and Colorectal Cancer Risk in Postmenopausal Women. J Natl Cancer Inst 2015; 107:

49. Green J, Czanner G, Reeves G, et al. Menopausal hormone therapy and risk of gastrointestinal cancer: nested case-control study within a prospective cohort, and meta-analysis. Int J Cancer 2012; 130:2387-96.

50. Williams NI, Reed JL, Leidy HJ, et al. Estrogen and progesterone exposure is reduced in response to energy deficiency in women aged 25-40 years. Hum Reprod 2010; 25:2328-39.
51. Dirx MJM, van den Brandt PA, Goldbohm RA, et al. Energy restriction early in life and colon carcinoma risk: results of The Netherlands Cohort Study after 7.3 years of follow-up. Cancer 2003; 97:46-55.

52. Feise RJ. Do multiple outcome measures require $\mathrm{p}$ values adjustment?. BMC Med Res Methodol 2002; $2: 8$ 